\title{
Percepção do abuso sexual na deficiência intelectual: uma revisão de literatura
}

\author{
Perception of sexual abuse in intellectual disability: a literature review \\ Percepción del abuso sexual en la discapacidad intelectual: revisión de la literatura
}

Recebido: 28/09/2021 | Revisado: 09/10/2021 | Aceito: 14/10/2021 | Publicado: 17/10/2021

\author{
Andreza Lima da Silva Cardoso \\ ORCID: https://orcid.org/0000-0001-6893-991X \\ Universidade Estácio de Sá, Brasil \\ E-mail: andrezalima.silva@hotmail.com \\ Edmilce de Fátima Domingos \\ ORCID: https://orcid.org/0000-0003-4464-7706 \\ Universidade Estácio de Sá, Brasil \\ E-mail: mibi165@hotmail.com \\ Kelvin Felix Braga \\ ORCID: https://orcid.org/0000-0003-3599-2946 \\ Universidade Estácio de Sá, Brasil \\ E-mail: letsshinetogether@hotmail.com \\ Maristela da Silva Amaral \\ ORCID: https://orcid.org/0000-0002-1438-4418 \\ Universidade Estácio de Sá, Brasil \\ E-mail: maristeladasilvaamaral@gmail.com \\ Ronilce Rozendo Amorim \\ ORCID: https://orcid.org/0000-0003-2291-6055 \\ Universidade Estácio de Sá, Brasil \\ E-mail: ronilceamorym@gmail.com \\ Andréa da Silva Gomes \\ ORCID: https://orcid.org/0000-0002-4760-0762 \\ Universidade Estácio de Sá, Brasil \\ E-mail: dealudovico2006@gmail.com \\ Priscila Cristina Pereira de Oliveira da Silva \\ ORCID: https://orcid.org/0000-0002-6304-7952 \\ Universidade Estácio de Sá, Brasil \\ E-mail: prioliveira0512@gmail.com \\ Marcelo Rodrigues Pessoa \\ ORCID: https://orcid.org/0000-0002-4605-5272 \\ Universidade Estácio de Sá, Brasil \\ E-mail: marcelo.pesso@ @otmail.com
}

\begin{abstract}
Resumo:
Introdução: A deficiência intelectual se caracteriza por um processo mental ou psicossocial abaixo da média, evidenciando que não apresentam desempenho esperado, tendo em vista, seu baixo desenvolvimento cognitivo, situação que pode prejudicar sua percepção acerca da realidade, sendo presa fácil para a prática de abuso sexual. Objetivo: Descrever por meio de estudos da literatura selecionada, situações de abuso sexual em pessoas com deficiência intelectual, tendo em vista, sua baixa capacidade de percepção da sua sexualidade. Sinalizando a fragilidade e vulnerabilidade do indivíduo portador de deficiência intelectual diante de situações de violência. Metodologia: Este estudo trata-se de uma Revisão Integrativa de Literatura, de abordagem qualitativa e descritiva, elaborada através da coleta de dados na Biblioteca Virtual em Saúde (BVS), no período de 2011 a 2020, seguindo os critérios de inclusão que foram textos completos e indexados na íntegra, disponíveis para leitura, em língua portuguesa, com recorte temporal de 10 anos. Como critério de exclusão foram descartados artigos em repetição ou que não estavam em concordância com a temática proposta. Após a aplicação dos critérios foram selecionados 08 artigos para compor este estudo. Resultados: Como resultado observou-se a importância do profissional em saúde na abordagem e no cuidado humanizado ao paciente com deficiência, vítima de abuso sexual e a urgência em discutir a sexualidade de pessoas com deficiência. Conclusão: É possível concluir que pessoas com Deficiência Intelectual necessitam de mais atenção de seus responsáveis e principalmente do poder público, através de políticas direcionadas evitando assim, possíveis abusos sexuais ou situações de violência.
\end{abstract}

Palavras-chave: Abuso sexual; Deficiência intelectual; Enfermagem; Sexualidade; Delito sexual.

\begin{abstract}
Introduction: Intellectual disability is characterized by a below-average mental or psychosocial process, showing that they do not perform as expected, in view of their low cognitive development,a situation that can impair their perception of reality, being easy prey for the practice of abuse sexual. Objective: Describe, through studies of selected
\end{abstract}


literature, situations of sexual abuse in people with intellectual disabilities, considering their ability to perceive sexuality. Signaling the fragility and vulnerability of individuals with intellectual disabilities in situations of violence. Method: This study is an Integrative Literature Review, with a qualitative and descriptive approach, elaborated through data collection in the virtual health library (VHL), in the period from 2011 to 2020, following the inclusion criteria, which were full texts and indexed in the in full, available for reading, in Portuguese, with a 10-year time frame. As an exclusion criterion, articles that were repeated or that did not comply with the proposed theme were discarded. After applying the criteria, 08 articles were selected to compose the study. Results: As results, the importance of the health professional in the approach and humanized care to the disabled patient, victim of sexual abuse and the urgency to discuss the sexuality of people with disabilities was observed. Conclusion: It is possible to conclude that people with ID need more attention from their guardians and mainly from the public power, through targeted policies thus avoiding possible sexual abuse or situations of violence.

Keywords: Sexual abuse; Intellectual disability; Nursing; Sexuality; Sexual offense.

\section{Resumen}

Introducción: La discapacidad intelectual se caracteriza por un proceso mental o psicosocial por debajo de la media, mostrando que no se desempeñan como se espera, dado su bajo desarrollo cognitivo, situación que puede perjudicar su percepción de la realidad, siendo presa fácil para la práctica de abuso sexual. Objetivo: Describir, a través de estudios de literatura seleccionada, situaciones de abuso sexual en personas con discapacidad intelectual, considerando su capacidad para percibir la sexualidad. Señalar la fragilidad y vulnerabilidad de las personas con discapacidad intelectual en situaciones de violencia. Método: Este Estudio es una Revisión Integrativa de la Literatura, con enfoque cualitativo y descriptivo, elaborado a través de la recolección de datos en la Biblioteca Virtual en Salud (BVS), en el período de 2011 a 2020, siguiendo los criterios de inclusión, los cuales fueron textos completos e indexados en el completo, disponible para lectura, en portugués, con un plazo de 10 años. Como criterio de exclusión se descartaron los artículos que se repitieron o que no cumplieron con la temática propuesta. Después de aplicar los criterios, se seleccionaron 08 artículos para componer el estudio. Resultados: En los resultados se observó la importancia de la salud profesional en el abordaje y atención humanizada al paciente discapacitado, víctima de abuso sexual y la urgencia de discutir la sexualidad de las personas con discapacidad. Conclusión: Es posible concluir que las personas con DI necesitan mayor atención por parte de los tutores y principalmente del poder público, a través de políticas focalizadas evitando así posibles abusos sexuales o situaciones de violencia.

Palabras clave: Abuso sexual; Discapacidad intelectual; Enfermería; Sexualidad; Delito sexual.

\section{Introdução}

A deficiência intelectual (DI) caracterizada por um processo mental e psicossocial abaixo da média esperada, muitas vezes, cercada de limitações tanto no processo cognitivo, como no adaptativo. Limitações que podem atingir as relações sociais e habilidades interpessoais. (Assumpção \& Sprovieri, 1993) Um indivíduo que apresenta um grau de deficiência tende a ter um prejuízo em seu processo de adaptação social, gerando perdas de caráter permanente. (Gorla, Araújo, \& Carminato, 2004)

Compreende-se que as pessoas com deficiência intelectual não apresentam desempenho esperado de acordo com a sua idade,evolução sexual ou sua condição social, tendo em vista o baixo desenvolvimento cognitivo, o que pode prejudicar sua individualidade e percepção da independência. Schwartzman (1999)

No entanto alguns autores afirmam que a grande maioria dos indivíduos com alguma deficiência intelectual e com leve comprometimento podem desenvolver autonomia ou responsabilidades relacionados ao autocuidado pessoal e independência frente as suas necessidades. (Coll, Marchesi, \& Palacios, 2004)

Uma pessoa com algum tipo de limitação pode provocar dentro do ambiente familiar uma sensação de frustração e sobrecarga contribuindo para situações de negligência e até mesmo de abusos, como maus-tratos físicos,estupros, falta de cuidados, má alimentação, vestuário inadequado, dentre outros, o que representa uma forma de negação e violência. (Ministério da Saúde, 2001)

Em uma pesquisa do IBGE realizada em 2002, havia quase três milhões de brasileiros com deficiência intelectual, 447.534 estão na faixa etária de 10 a 19 anos de idade (IBGE, 2002). Sendo um assunto pouco discutido, quando se fala sobre o despertar da sexualidade genital. Sendo um tabu a abordagem dos principais aspectos sexuais relacionados a pessoa com deficiência intelectual, evidenciando um preconceito estrutural e uma grave violação de direitos. Almeida (2009) 
É possível perceber no decorrer da pesquisa bibliográfica que ainda existe a crença de que as pessoas com deficiência intelectual são assexuadas ou infantilizadas. Outros acreditam na hipersexualidade desses indivíduos de forma bizarra, agressiva e por vezes animalescas. Construção esta que se dá devido a deficiência de um papel sexual pré-estabelecido desses indivíduos ao longo do seu desenvolvimento. Limitação que se constrói através da privação do convívio social, falta de informação, deturpação de informações e aceitação social. (Maia \& Camossa, 2003)

A seleção e escolha do tema em questão para a elaboração da pesquisa, partiu de uma inquietação de presenciar situações de violência ocorridas no seio familiar tendo como vítima dessa brutalidade pessoas com deficiência intelectual, e que em razão de sua deficiência não consegue relatar ou até mesmo diferenciar o que de fato é um abuso sexual.

O objetivo geral é descrever por meio de estudos da literatura selecionada, situações de abuso sexual em pessoas com deficiência intelectual, tendo em vista, sua baixa capacidade de percepção da sua sexualidade. Sinalizando a fragilidade e vulnerabilidade do indivíduo portador de deficiência intelectual diante de situações de violência. E como objetivo específico tem-se o intuito de descrever os possíveis agravos dos abusos sexuais em pessoas com deficiência intelectual, sugestionar uma educação permanente sobre a abordagem do profissional enfermeiro na prática do acolhimento à vítima de abuso sexual e analisar o papel importante da família nesta conjectura, como protagonista na intenção de proteger a vítima.

O artigo busca contribuir para que os profissionais de saúde possam ter um pensamento crítico e reflexivo, no âmbito de combater o preconceito e a desinformação levando a família da vítima a não procurar ajuda. É preciso e urgente falar sobre a temática da violência sexual acometida a pessoas com algum tipo de deficiência.

Pretende-se neste trabalho ressaltar a importância de políticas públicas e o envolvimento de todos os agentes da sociedade no combate a essa epidemia silenciosa e enclausurada, ressaltando o papel do profissional de saúde em traçar estratégias fundamentais no intuito de uma abordagem pautada pela ética e principalmente através do cuidado humanizado no atendimento a pessoa com deficiência intelectual vítima de violência sexual.

\section{Metodologia}

Este estudo trata-se de uma revisão integrativa de literatura, de abordagem qualitativa, o que proporciona uma síntese do conhecimento e a incorporação da aplicabilidade de resultados de estudos significativo na prática. (Souza, Silva, \& Carvalho, 2010)

A pesquisa de abordagem qualitativa é um método de estudo que busca descrever e explicar os fenômenos pesquisados, através de estudos observacionais e entrevistas contextuais. Devendo esta metodologia ser estruturada a modo de responder à questão da pesquisa formulada, com uma análise lógica dos dados levantados, para fomentar uma conclusão coerente, sendo seu objetivo principal a observância dos fenômenos apresentados. (Cyriaco, Nunn, Amorim, Falcão, \& Moreno, 2017)

Bardin (2016), define que a pesquisa qualitativa é a que se fundamenta principalmente em análises qualitativas, caracterizando-se, em princípio, pela não utilização de instrumental estatístico na análise dos dados.

No entanto, para Gerhardt \& Silveira (2009), "a pesquisa descritiva tende a exigir do investigador uma gama de informações sobre o tema a ser investigado. Salienta que este tipo de estudo tem por pretensão descrever os fatos e fenômenos de determinada situação e realidade.

A proposta de construção de Revisão Integrativa de acordo com Mendes, Silveira e Galvão (2008) é um método com etapas distintas a serem seguidas. De acordo com esses critérios, esta revisão deve conter seis etapas, sendo elas: Estabelecimento da hipótese ou questão de pesquisa; Amostragem ou busca na literatura; Categorização dos estudos; avaliação dos estudos incluídos na revisão; Interpretação dos resultados; Síntese do conhecimento ou apresentação da revisão. 
A pesquisa de abordagem qualitativa não se preocupa com o aprofundamento da compreensão de um grupo social, de uma organização, se opondo ao pressuposto que defende um modelo único de pesquisa para todas as ciências, já que as ciências sociais têm sua especificidade pressupondo uma metodologia própria. Goldenberg (1997)

Tratando-se de pesquisa descritiva, será aborda a descrição do problema investigado, o que possibilita conhecer os fenômenos investigados, aprofundando seus limites em uma realidade específica. (Polit \& Beck, 2011)

Para a construção e elaboração da questão norteadora utilizou o método voltado para a pesquisa clínica. A estratégia PICo possui um acrônimo para paciente, intervenção e contexto. Sendo elementos fundamentais na formulação da questão norteadora para assim ser realizada a busca bibliográfica. (Santos, Pimenta, \& Nobre, 2007)

Quadro 1: Estratégia PICo, para definição da questão norteadora.

\begin{tabular}{|l|l|l|}
\hline Acrônimo & Descrição & Componentes da questão \\
\hline P & Participantes & Deficiente intelectual \\
\hline I & Intervenção & Compreender a percepção da vítima sobre o abuso sexual \\
\hline Co & Contexto & $\begin{array}{l}\text { Humanização dos cuidados prestados a pessoa com deficiência diante de } \\
\text { situações que configurem abuso sexual. }\end{array}$ \\
\hline
\end{tabular}

Fonte: Elaborada pelos autores.

O processo de interpretação dos dados é considerado a fase mais complexa, sendo necessário a iniciação do estudo com um entendimento e incorporação de definições filosóficas e epidemiológicas que estruturam a pesquisa, desde o processo de seleção do objeto de estudo da pesquisa. Minayo (2011)

Os documentos foram obtidos e escolhidos estudos por meio de coleta de dados de publicações de autores de referência na área com posterior leitura crítica dos títulos e resumos, na Biblioteca Virtual em Saúde (BVS), utilizando a base de dados: Scientific Eletronic Online (SCIELO), Literatura Latino-Americana em Ciências de Saúde (LILACS) e Base de Dados de Enfermagem (BDENF), no período de março a maio de 2021.

Foram estabelecidos os seguintes Descritores em Ciência da Saúde (DESC) para a busca e seleção de dados: "Deficiência intelectual"; "Enfermagem"; "Delito sexual”; "Sexualidade”;“Abuso sexual”, utilizando o operador booleano “AND” entre eles na pesquisa.

Foram definidos os seguintes critérios de inclusão: artigos indexados na íntegra e disponíveis para leitura, em Língua Portuguesa e texto completo, com recorte temporal de 10 anos (2011 a 2020). Como critérios de exclusão foram descartados os artigos em repetição ou que não estavam em concordância com a temática proposta. Após empregar os critérios de inclusão e exclusão na busca bibliográfica, foi possível observar uma imensa escassez de publicações e estudos referentes a temática, emergindo um total de 08 artigos para compor este trabalho, alinhados ao tema proposto.

\section{Resultados e Discussão}

Após leitura minuciosa para melhor compreensão do conteúdo estudado, foi possível fazer a avaliação dos dados, com a identificação dos principais pontos que se aplicam ao contexto do objetivo da pesquisa.

O Quadro 2 apresenta as características mais importantes dos artigos utilizados, como: título, nome dos autores, periódico, objetivos, resultados e conclusão. 
Quadro 2- Características dos artigos analisados

\begin{tabular}{|c|c|c|c|c|c|}
\hline TÍTULO & AUTORES & PERIÓDICOS & OBJETIVOS & RESULTADO & CONCLUSÃO \\
\hline $\begin{array}{l}\text { Opinião de } \\
\text { professores } \\
\text { sobre a } \\
\text { sexualidade } \\
\text { e educação } \\
\text { sexual de } \\
\text { alunos com } \\
\text { deficiência } \\
\text { intelectual }\end{array}$ & $\begin{array}{l}\text { Ana Claudia } \\
\text { Bortolozzi } \\
\text { Maia; } \\
\text { Verônica Lima } \\
\text { dos Reia- } \\
\text { Yamauti; } \\
\text { Rafaela de } \\
\text { Almeida } \\
\text { Schiavo; } \\
\text { Vera Lúcia } \\
\text { Messias Fialho } \\
\text { Capellini; } \\
\text { Tânia Gracy } \\
\text { Martins do } \\
\text { Valle }\end{array}$ & $\begin{array}{l}\text { Estudos de } \\
\text { Psicologia. } \\
\text { Campinas. } \\
\text { 427-435. Julho- } \\
\text { setembro, 2015. }\end{array}$ & $\begin{array}{lr}\text { Investigar } & \text { a } \\
\text { opinião } & \text { de } \\
\text { professores que } & \text { quarticiparam de } \\
\text { paro } & \text { de } \\
\text { um curso } & \text { formação } \\
\text { continuada em } \\
\text { práticainclusivos } \\
\text { que, dentre outros } \\
\text { temas, abordou as } \\
\text { questões } \\
\text { sexualidade de } \\
\text { educação sexual } \\
\text { de alunos com } \\
\text { deficiência } \\
\text { intelectual. }\end{array}$ & $\begin{array}{l}\text { Os resultados } \\
\text { especificaram as } \\
\text { respostas dos } \\
\text { professores } \\
\text { participantes sobre as } \\
\text { formas de } \\
\text { sexualidade que } \\
\text { percebiam em seus } \\
\text { alunos. }\end{array}$ & $\begin{array}{l}\text { Foi possível } \\
\text { concluir através dos } \\
\text { relatos que os } \\
\text { alunos } \\
\text { instituição } \\
\text { expressavam a sua } \\
\text { sexualidade } \\
\text { geralmente } \\
\text { verbalizações } \\
\text { corriqueiras, ou em } \\
\text { situações } \\
\text { relacionadas ao } \\
\text { contexto social em } \\
\text { que estavam } \\
\text { inseridos. }\end{array}$ \\
\hline TÍTULO & AUTORES & PERIÓDICOS & OBJETIVOS & RESULTADOS & CONCLUSÃO \\
\hline $\begin{array}{l}\text { Sexualidade } \\
\text { e deficiência } \\
\text { intelectual: } \\
\text { Narrativa de } \\
\text { pais de } \\
\text { adolescentes }\end{array}$ & $\begin{array}{l}\text { Olga Maria } \\
\text { Bastos; Suely } \\
\text { Ferreira } \\
\text { Deslandes }\end{array}$ & $\begin{array}{l}\text { Physis Revista de } \\
\text { Saúde Coletiva, Rio } \\
\text { de Janeiro, } \\
22[3]: 1031- \\
1046,2012 \text {. }\end{array}$ & $\begin{array}{l}\text { Conhecer as } \\
\text { manifestações } \\
\text { sexuais } \\
\text { vivenciadas por } \\
\text { adolescentes com } \\
\text { deficiência. }\end{array}$ & $\begin{array}{l}\text { Pode se observar } \\
\text { através de narrativas } \\
\text { dos responsáveis, } \\
\text { manifestações como } \\
\text { masturbação, medo } \\
\text { de abusos físicos } \\
\text { além de indagações } \\
\text { sobre as mudanças } \\
\text { corporais. }\end{array}$ & $\begin{array}{l}\text { Este estudo conclui } \\
\text { que existe } \\
\text { aparentemente um } \\
\text { preconceito e uma } \\
\text { inadequação entre o } \\
\text { desenvolvimento } \\
\text { físico e as } \\
\text { manifestações } \\
\text { sexuais como } \\
\text { narrativa dos pais } \\
\text { entrevistados. }\end{array}$ \\
\hline
\end{tabular}

\begin{tabular}{|c|c|c|c|c|c|}
\hline TÍTULO & AUTORES & PERIÓDICOS & OBJETIVO & RESULTADOS & CONCLUSÃO \\
\hline $\begin{array}{l}\text { Vivência da } \\
\text { sexualidade a } \\
\text { partir do relato } \\
\text { de pessoas } \\
\text { com } \\
\text { deficiência } \\
\text { intelectual }\end{array}$ & $\begin{array}{l}\text { Ana Claúdia } \\
\text { Bortolozzi } \\
\text { Maia }\end{array}$ & $\begin{array}{l}\text { Psicologia em } \\
\text { Estudo, Maringá, v. } \\
21, \text { n.P. } 77-88 \text {, } \\
\text { jan } / \text { mar. } 2016 .\end{array}$ & $\begin{array}{l}\text { Investigar a } \\
\text { vivência da } \\
\text { sexualidade a } \\
\text { partir de relatos } \\
\text { de homens e } \\
\text { mulheres com } \\
\text { DI. }\end{array}$ & $\begin{array}{l}\text { Os investigados nesta } \\
\text { pesquisa } \\
\text { demonstraram } \\
\text { algumas dificuldades } \\
\text { em relatar suas } \\
\text { vivências sexuais, } \\
\text { seus desejos e suas } \\
\text { inquietações. }\end{array}$ & $\begin{array}{l}\text { Este estudo } \\
\text { concluiu que diante } \\
\text { dos relatos, há } \\
\text { inúmeros ensejos e } \\
\text { expectativas } \\
\text { relacionados ao } \\
\text { casamento, } \\
\text { constituir família, } \\
\text { mesmo em } \\
\text { situações de } \\
\text { vulnerabilidade que } \\
\text { esses desejos são } \\
\text { iguais } \\
\text { semelhante } \\
\text { demais. aos }\end{array}$ \\
\hline TÍTULO & AUTORES & PERIÓDICOS & OBJETIVO & RESULTADOS & CONCLUSÃO \\
\hline $\begin{array}{l}\text { Entrelace } \\
\text { entre Gênero, } \\
\text { Sexualidade e } \\
\text { Deficiência: } \\
\text { Uma História } \\
\text { Feminina de } \\
\text { Rupturas e } \\
\text { Empoderamen } \\
\text { to }\end{array}$ & $\begin{array}{l}\text { Taísa Caldas } \\
\text { Dantas; } \\
\text { Jackeline } \\
\text { Susann Souza } \\
\text { Silva; } \\
\text { Maria Eulina } \\
\text { Pessoa de } \\
\text { Carvalho }\end{array}$ & $\begin{array}{l}\text { Rev. Bras. Ed. Esp., } \\
\text { Marília, v. } 20, \text { n. 4, } \\
\text { p. } 555-568, \text { Out- } \\
\text { Dez. } 2014 .\end{array}$ & \begin{tabular}{lr} 
Fazer & uma \\
análise & do \\
processo de & de \\
empoderamento & \multicolumn{2}{l}{ de pessoas com } \\
Deficiência & e \\
como & esse \\
processo & \\
influencia & a \\
identidade de & gênero \\
sexualidade.
\end{tabular} & \begin{tabular}{l}
\multicolumn{3}{l}{ Este estudo traz uma } \\
contribuição \\
investigação sobre as \\
vivencias da \\
sexualidade, seu \\
empoderamento \\
como pessoa e seu \\
reconhecimento da \\
sua identidade de \\
gênero.
\end{tabular} & $\begin{array}{l}\text { Este trabalho traz } \\
\text { como conclusão a } \\
\text { história de } \\
\text { superação de uma } \\
\text { mulher portadora de } \\
\text { deficiência } \\
\text { intelectual que } \\
\text { diante de inúmeras } \\
\text { situações de } \\
\text { preconceito } \\
\text { resistência, } \\
\text { consegueatravés do } \\
\text { empoderamento } \\
\text { feminino sua } \\
\text { individualidade. }\end{array}$ \\
\hline
\end{tabular}




\begin{tabular}{|c|c|c|c|c|c|}
\hline TÍTULO & AUTORES & PERIÓDICO & OBJETIVOS & RESULTADOS & CONCLUSÃO \\
\hline $\begin{array}{l}\text { Sexualidade } \\
\text { na } \\
\text { deficiência } \\
\text { intelectual: } \\
\text { Uma análise } \\
\text { das } \\
\text { percepções } \\
\text { de mães de } \\
\text { adolescentes } \\
\text { especiais }\end{array}$ & $\begin{array}{l}\text { Patrícia } \\
\text { Mattos } \\
\text { Caldeira Brant } \\
\text { Littig; Daphne } \\
\text { Rajab Cárdia; } \\
\text { Luciana } \\
\text { Bicalho Reis; } \\
\text { Erika da Silva } \\
\text { Ferrão }\end{array}$ & $\begin{array}{l}\text { Rev. Bras. Esp., } \\
\text { Marília, v. 18, n. } \\
\text { 3,p. } 469-486 \text {, jul- } \\
\text { set., } 2012 .\end{array}$ & $\begin{array}{l}\text { Fazer uma } \\
\text { análise } \\
\text { investigativa } \\
\text { através de relatos } \\
\text { de mães de } \\
\text { jovens sobre a } \\
\text { passagem entre a } \\
\text { infância e a fase } \\
\text { adulta, e o } \\
\text { desenvolvimento } \\
\text { da sexualidade, } \\
\text { suas reações e } \\
\text { mudanças } \\
\text { psicológicas, } \\
\text { físicas e sociais. }\end{array}$ & $\begin{array}{l}\text { Este artigo traz como } \\
\text { resultados a forma } \\
\text { como as mães de } \\
\text { jovens } \\
\text { deficiência intelectual, } \\
\text { tratam seus filhos de } \\
\text { forma infantilizada e } \\
\text { até } \\
\text { discriminada. mesmo }\end{array}$ & $\begin{array}{l}\text { Este artigo traz como } \\
\text { conclusão a idéia } \\
\text { central de que as } \\
\text { mães com filhos com } \\
\text { alguma deficiência } \\
\text { consideram como } \\
\text { seres assexuados ou } \\
\text { ausentes } \\
\text { sexualidade, não } \\
\text { reconhecendo uma } \\
\text { identidade sexual em } \\
\text { seus filhos. }\end{array}$ \\
\hline TÍTULO & AUTORES & PERIÓDICO & OBJETIVOS & RESULTADOS & CONCLUSÃO \\
\hline $\begin{array}{l}\text { Relação } \\
\text { entre crimes } \\
\text { sexuais e } \\
\text { transtomos } \\
\text { mentais e do } \\
\text { desenvolvim } \\
\text { ento }\end{array}$ & $\begin{array}{l}\text { Alexandre } \\
\text { Martins } \\
\text { Valença; } \\
\text { Isabella } \\
\text { Nascimento, } \\
\text { AntônioEgídio } \\
\text { Nadi }\end{array}$ & $\begin{array}{l}\text { RevPsiq Clín. } \\
\text { 40(3): } 97-104, \\
2013 .\end{array}$ & $\begin{array}{l}\text { Este trabalho tem } \\
\text { como objetivo } \\
\text { analisar a relação } \\
\text { entre os crimes } \\
\text { sexuais e } \\
\text { transtomos } \\
\text { mentais através } \\
\text { de pesquisa } \\
\text { bibliográfica. }\end{array}$ & $\begin{array}{l}\text { Este estudo traz como } \\
\text { resultados que os } \\
\text { transtomos mentais } \\
\text { estão relacionados } \\
\text { com crimes sexuais e } \\
\text { frequentemente a } \\
\text { patologias como } \\
\text { esquizofrenia, } \\
\text { transtomo mental e } \\
\text { outros. }\end{array}$ & $\begin{array}{l}\text { Este artigo traz como } \\
\text { conclusão a detecção } \\
\text { e tratamento precoce } \\
\text { de transtomos } \\
\text { mentais } \\
\text { diagnosticados nos } \\
\text { indivíduos ofensores } \\
\text { sexuais, contribuindo } \\
\text { para uma possível } \\
\text { diminuição na } \\
\text { reincidência na } \\
\text { comportamento } \\
\text { sexual. }\end{array}$ \\
\hline
\end{tabular}

\begin{tabular}{|c|c|c|c|c|c|}
\hline TITULO & QUALIS & OBJETIVO & $\begin{array}{l}\text { TIPO DE } \\
\text { PESQUISA }\end{array}$ & $\begin{array}{l}\text { DADOS } \\
\text { EVIDÊNCIADOS }\end{array}$ & $\begin{array}{l}\text { NIVEL DE } \\
\text { EVIDENCIA }\end{array}$ \\
\hline $\begin{array}{l}\text { Sexualidade e } \\
\text { deficiência } \\
\text { intelectual: } \\
\text { narrativa de pais de } \\
\text { adolescentes. }\end{array}$ & B1 & $\begin{array}{l}\text { Conhecer como pais } \\
\text { de filhos com } \\
\text { deficiência, } \\
\text { vivenciam a } \\
\text { sexualidade de seus } \\
\text { filhos. }\end{array}$ & Quantitativa & $\begin{array}{l}\text { A sexualidade das } \\
\text { pessoas com DI, } \\
\text { perpassa por situações de } \\
\text { preconceitos e } \\
\text { impossibilidades de } \\
\text { concretização da relação } \\
\text { sexual, e o medo dos pais } \\
\text { dos filhos sofrerem } \\
\text { abusos, além do } \\
\text { autocontrole dos pais }\end{array}$ & Nivel IV \\
\hline $\begin{array}{l}\text { Opinião de } \\
\text { professores sobre a } \\
\text { sexualidade e a } \\
\text { educação sexual de } \\
\text { alunos com } \\
\text { deficiência } \\
\text { intelectual. }\end{array}$ & $\mathrm{A} 1$ & $\begin{array}{l}\text { Através de um } \\
\text { questionário, } \\
\text { investigar opiniões de } \\
\text { professores sobre a } \\
\text { sexualidade de seus } \\
\text { alunos com } \\
\text { deficiência. }\end{array}$ & $\begin{array}{l}\text { Quantitativo } \\
\text { Qualitativo }\end{array}$ & $\begin{array}{l}\text { Foi possivel evidenciar } \\
\text { que a maioria dos } \\
\text { professores consegue } \\
\text { perceber } \\
\text { comportamentos sexuais } \\
\text { de seus alunos com } \\
\text { deficiencia intelectual. }\end{array}$ & Nivel IV \\
\hline $\begin{array}{l}\text { Vivência da } \\
\text { sexualidade a partir } \\
\text { do relato de } \\
\text { pessoas com } \\
\text { deficiência } \\
\text { intelectual. }\end{array}$ & A1 & $\begin{array}{l}\text { Investigar a vivência } \\
\text { da sexualidade de } \\
\text { homens e mulheres } \\
\text { com deficiência } \\
\text { intelectual. }\end{array}$ & $\begin{array}{l}\text { Qualitativa } \\
\text { Descritiva }\end{array}$ & $\begin{array}{l}\text { E possivel evidenciar as } \\
\text { dificuldades encontradas } \\
\text { por homens e mulheres } \\
\text { com DI em verbalizar } \\
\text { conceitos sobre sua } \\
\text { sexualidade e seus } \\
\text { ensejos diários. }\end{array}$ & Nivel V \\
\hline $\begin{array}{l}\text { Entrelace entre } \\
\text { gênero, sexualidade } \\
\text { e deficiência: Uma } \\
\text { história feminina } \\
\text { de rupturas e } \\
\text { empoderamento }\end{array}$ & B1 & $\begin{array}{l}\text { Fazer uma análise } \\
\text { sobre o processo de } \\
\text { empoderamento e o } \\
\text { conhecimento dos } \\
\text { seus direitos } \\
\text { influenciando no } \\
\text { reconhecimento da } \\
\text { sua identidade de } \\
\text { gênero. }\end{array}$ & Qualitativa & $\begin{array}{l}\text { Este artigo evidencia } \\
\text { através de relatos que a } \\
\text { deficiência contribui para } \\
\text { a invisibilidade da } \\
\text { própria sexualidade, } \\
\text { necessitando de um } \\
\text { enfrentamento o o } \\
\text { exercicio de auto } \\
\text { advocacia. }\end{array}$ & Nivel IV \\
\hline
\end{tabular}

Fonte: Autores. 
A partir dessa análise, emergiram 2 categorias temáticas, sendo a primeira categoria intitulada de "Deficiência intelectual, percepção da sexualidade e o abuso sexual". A segunda categoria temática é "Gênero, sexualidade e questões etnográficas: situações que influenciam ou facilitam a prática do abuso sexual".

Categoria 1: Deficiência intelectual, percepção da sexualidade e o abuso sexual

De acordo com o senso público, os portadores de deficiência intelectual, na maioria dos casos os jovens, não têm sexualidade ou têm de forma não controlada. Para Gregori (2008), quando o assunto é a sexualidade dos jovens, nota-se alguns preconceitos já existentes neste campo, tratando-se da população com DI, como exemplo, no Reino Unido, se for negado os serviços de uma prostituta a um indivíduo do sexo masculino considera-se uma violação de seus direitos, o que já não ocorre da mesma forma com pessoa do sexo feminino nas mais diversas faixas etárias e jovens do sexo masculino menores de 22 anos, pois a eles essa conduta não é aplicada. Por isso, é importante considerar que os adolescentes com deficiência, possuem necessidades, impulsos, desejos e emoções normais, vivenciando questões de natureza sexual como qualquer indivíduo portador ou não de deficiência. (Bastos \& Deslandes, 2005)

A juventude é marcada por um período de alterações físicas, comportamentais e sentimentais, no qual se espera a mudança da criança para a maior idade e por possuírem um processo mental notadamente inferior à média acompanhada de limitações no funcionamento adaptativo em algumas áreas como: comunicação, autocuidado, habilidades sociais, interpessoais e acadêmicas, auto suficiência, lazer entre outros, essa transição acaba sendo mais complicada e difícil de lidar para os adolescentes com Deficiência Intelectual. Dessa forma, acabam não apresentando um desempenho esperado de acordo com sua idade ou condição social, embora a grande maioria, apresentem um comportamento leve, sendo capaz de desenvolver algum grau de autonomia, independência ou assumir responsabilidades pessoais. (Assumpção \& Sprovieri, 1993)

Diante desses questionamentos e mudanças na concepção geral sobre a sexualidade e a criação de organizações sociais voltadas para inclusão, deixaram de focar exclusivamente na deficiência intelectual e passaram a enxergá-los como indivíduos que possuem desejos e necessidades, devendo-se assim, sua sexualidade ser respeitada como um direito inerente a todos os indivíduos e vivenciada conforme a individualidade de cada um. (Maia \& Camossa, 2003)

Assim, os direitos das pessoas com deficiência começaram a ser discutidos, garantindo os direitos humanos das pessoas com deficiência, dentre esses direitos foram inclusos os sexuais. No Brasil as Políticas Nacionais de Saúde da Pessoa com Deficiência e de Direitos Sexuais e Reprodutivos, orientam que pessoas com deficiência têm direito à livre expressão de sua sexualidade com acesso às informações sobre o sexo seguro, a prevenção de ISTs, além de métodos e técnicas de reprodução. (Ministério da Saúde, 2005)

Embora seja comum a crença de que as pessoas com Dl são assexuadas, ou até mesmo vistas como "eternas crianças ou angelicais", suas concepções são dadas pela privação do convívio social, pela carência e deturpação das informações recebidas, bem como, pela não aceitação social de seus desejos, necessidades e capacidades sexuais, perante a sociedade são vistas como deficientes ou retardados em seu desenvolvimento sexual e afetivo, possuindo também uma deficiência emocional, sendo assim, considerados incapazes de estabelecer relações amorosas profundas e duradouras, sendo prejudicados e impedidos de se casar, gozar de filhos ou conduzir uma vida sexual frequente. Giami (2004)

Alguns autores como Bastos e Deslandes (2005) em seus estudos. Relataram que alguns pais de adolescentes com DI, relataram que foi possível observar um comportamento de autoerotismo que no caso dos pais de meninos, foi considerado algo que ocorria devido a puberdade, enquanto para os pais de meninas, era algo instintivo sem maldade.

Segundo relatos dos jovens com deficiência e esses estudos foram obtidos com apresentação de desenho da figura humana, bonecos sexuados e pranchas com cenas sobre namoro, casamento, autoerotismo, jogos sexuais, parto e abuso sexual, onde através desse comportamento os autores perceberam que eles tinham noção de uma identidade de gênero e conhecimentos 
difusos e incompletos sobre sexualidade, mostrando a necessidade de implementação de programas de educação sexual. (Maia \& Camossa, 2003)

Por isso, a sexualidade é um tema polêmico, mesmo em uma sociedade inclusiva, pois trata-se de um duplo tabu: por um lado, a sexualidade é representada por valores e concepções sociais diversas e por outro a Deficiência intelectual implica em limitações cognitivas e carrega o estigma da "diferença" e da desvantagem social. Onde as dificuldades encontradas na sexualidade dessas pessoas acontecem mais por motivos psicológicos e sociais, do que orgânicos relacionados a deficiência ou as síndromes.

A violência contra pessoas do sexo masculino e principalmente do sexo feminino é um crime frequente e um ato agressivo baseado na diferença de gênero, o que resulta em sofrimentos e perdas físicas, sexuais e dos fenômenos mentais, ainda coação de tais práticas, constrangimento e privação da autonomia, quer dizer na vida externa ou particular. Esta agressão pode ser cometida por base de abusos, estupros ou atentado violento ao pudor e atinge pessoas do sexo feminino de qualquer intervalo estático, condição social e etnia, e vários ofensores são conhecidos das vítimas e nas maiorias dos casos, fazem parte do círculo familiar ou meio social em que vivem. (Villela \& Lago, 2007)

As altas taxas de violência resultou na criação da lei federal n. 10.778/2003 que estabelecendo a notificação dos casos dos violência. (Ministério da Saúde, 2003)

Os indivíduos com deficiência intelectual, devido a implicação da área linguístico-cognitiva, podem ser levianamente conquistada e revelam-se desprotegidas a assédio sexuais, uma vez que não obtém a comunicação adequado, para tal a sua defesa frente ao atentado, como para denunciar. (Curcino, Rodrigues, Maia, \& Palamim, 2006)

$\mathrm{O}$ fato de as vítimas serem solteiras reforça a ideia delas serem indefesas, dependentes e carentes de cuidados. Tal vulnerabilidade se justifica a partir das relações que poderiam ser de confiança e proteção, no entanto, são usadas como desculpa para a violência. (Ribeiro, 2005)

Discutindo exclusivamente da violência sexual, o indivíduo do sexo feminino com deficiência intelectual sofre maiores riscos como não incapacitada em função de adversidade na convicção e em carência na capacidade sociais que resultam em maior vulnerabilidade, falta de conhecimento em como se defender do abuso; falta de conhecimento sobre comportamento sexual apropriado ou devido a dependência excessiva de terceiros. (Barros, Williams, \& Brino, 2008)

Faz-se necessário que se entenda que, mesmo não havendo sequelas físicas, as consequências da violência psicológica são profundas, com marcas que vão muito além das lesões aparentes. (Ferraz \& Labronici, 2009)

Os abusos sexuais é um sério problema que continuamente confronta a nossa sociedade, incluindo um comportamento em que há ou não contato físico, envolvendo vítimas de ambos os sexos e intervalo de idades, ficando assinalado um tipo de conduta violento. Entende-se como violência sexual, o toque sexual permanente, investida ou intimidação, sem que haja aceitação do indivíduo, ou esta esteja incapacitado de dar essa aceitação. (Gonçalvez \& Vieira, 2004)

Existem estimativas mundiais de que entre $10 \%$ e $16 \%$ dos homens e entre $20 \%$ e $27 \%$ das mulheres foram vítimas de abuso sexual na infância. A investigação de delitos da Inglaterra (The British Crime Survey), por exemplo, fez uma pressuposição de que uma em cada dez individuo do sexo feminino já foi sexualmente vitimizada na adolescência e que menos de um em cada cinco episódio de violação sexual contra individuo do sexo feminino a seguimento em ação de policiamento. (Baltieri \& Andrade, 2008)

A doença mental não está incluída entre os fatores de risco para o cometimento de estupro, de acordo com estudos epidemiológicos ou abuso sexual em alguns estudos de revisão. Sptizber (1999)

Todavia, ainda não há aceitação na literatura sobre o conceito dessa associação. Porém, fatores de risco para a perpetração de crimes sexuais incluem associação de aspectos do desenvolvimento (tais como abuso sexual na puerícia) e 
fragilidade pessoal (sobretudo delírio sexuais divergente e episódios acionadores, como excesso de substâncias). (Fazel, Sjösted, Langström, \& Grann, 2007)

Categoria 2: Gênero, sexualidade e questões etnográficas: situações que influenciam ou facilitam a prática do abuso sexual

A vivência e desafios de uma pessoa do sexo feminino e masculino compartilham dos intensos desdobramentos pessoais, como empoderamento, sucesso acadêmico e na vida pessoal, namorar, estudar, trabalhar, morar sozinho e até mesmo viajar. Ainscow (1999)

É mostrado que o grupo social dos indivíduos com deficiência tem sofrido constante processos de exclusão, impossibilitando-as de desfrutar dos direitos humanos básicos, como o direito à sexualidade a educação, à cultura e ao lazer. (Carvalho, Andrade, \& Menezes, 2010)

Desencadeando experiências de maus tratos, perseguição, opressão, silenciamento ou até mesmo situações de mutilação, repercutindo numa história de vulnerabilidade desde a antiguidade. Nesse sentido especifica sobre o conceito de gênero como categoria antológica que considera as diferenças e as desigualdades atribuídos através de ambos os sexos feminino e masculino que ganham sentido através do sistema simbólicos culturais que designam masculinidade e feminilidade como um conjunto de qualidades opostas e hierárquica no marco de ginecofobia e do patriarcado. (Carvalho et al., 2010)

As relações de gênero são fortemente marcadas nas pessoas do sexo feminino com deficiência, pois, devido aos históricos processo de infantilização e dependência familiar em que estão submergidas as características de fragilidade feminina são intensificadas. E assim são protegidas pela família em razão da agressão e abuso sexual e, constantemente são vistas como incapazes de exercer os papeis que são concedidas as mulheres sem deficiência tais como constituir família, cuidar de filhos e das atividades domésticas. Hall (1992)

No entanto, considerando que ser pessoas do sexo masculino e feminino com deficiência depende do contexto históricos diferenciados, relações étnico-raciais, socioeconômico fazendo com que as identidades não sejam fixas e ambos os sexos assumam diferentes papéis. Durante o período de pesquisas em uma APAE de BRASÍLIA em 2012, foi realizado e acompanhado algumas atividades desenvolvidas nas instituições de ensino, com 9 estudantes, sendo 4 pessoas do sexo masculino e 5 do sexo feminino na faixa etária de 17 a 54 anos de idade. Os primeiros grupos a serem analisados foram os professores e profissionais, onde esses profissionais compreendiam a deficiência e a sexualidade dos estudantes, como pessoas anormais (como falta, incapacidade e anormalidade). Por tal fato, os professores organizaram e classificaram a sexualidade dos estudantes das associações por um referencial constitutivamente anormal e por isso cheio de poder perigoso. (Douglas, 1976)

A sexualidade periférica, ou seja, a sexualidade das crianças, dos loucos, dos criminosos, acrescentaria pessoas com deficiência, são elementos constitutivos para se pensar a sexualidade pois indivíduos ditos normais. Expressando-o "todas estas imagens, então apenas entrevistas, tem agora de acometer para tomar a palavra e fazer a difícil declarar daquilo que são. Foucault (1993)

Não são menos condenados, mas são escutados, e se novamente for perguntado, a sexualidade regular será a partir dessa sexualidade periférica através de um movimento, no século XXI não se confirmou a aspiração republicana de educação como um direito humano, observou-se nas últimas décadas a ampliação de matrículas de estudantes antes excluídos do ensino regular dentre esses muitos são indivíduos com deficiência intelectual. Esse processo tem sido nomeado de Educação Inclusiva, paradigma educacional baseado nos direitos humanos que combina igualdade e diferença como valores e avança em relação a equiparação de oportunidades. (Gal, Schreur, \& Engel-Yeger, 2010)

A pauta entre a educação e a sexualidade tem sido foco na prática e na área da educação e da psicologia. Constituindo um tema atual que não pode ser esquecido quando se fala em sociedade inclusiva. (Heighway \& Webster, 2008) 
Os mitos sobre sexualidade e deficiência refletem uma negação da sexualidade desses indivíduos e muitos das dificuldades dos profissionais, familiares e comunidades a esse respeito decorrem de concepções preconceituosas e desinformações. (Maia \& Ribeiro, 2010)

É comum o profissional da educação enfrentar dificuldades na unidade educacional com a sexualidade dos estudantes, em razão da falta de conhecimento ou de crenças inadequados ocasionando dificuldades no diálogo sobre sexualidade com os estudantes. Gerando temores e inseguranças diante do tema sexualidade, resistências da escola ou da família dos estudantes. (Albuquerque \& Almeida, 2010)

\section{Conclusão}

Foi possível concluir através desta revisão que pessoas com deficiência intelectual necessitam de mais atenção de seus tutores no sentido de evitar possíveis abusos sexuais, bem como situações de violência de uma forma geral.

É preciso fomentar uma reflexão sobre a importância da percepção que esses indivíduos, muitas vezes reclusos da sociedade têm sobre situações envolvendo abuso sexual, seus questionamentos frente à essa situação que é bastante presente na sociedade.

É de grande valia estabelecer parcerias entre o poder público e a iniciativa privada através de políticas públicas para o enfrentamento e o combate à violência abrangendo também as pessoas com deficiência intelectual.

Compreende-se o papel essencial do profissional de saúde na abordagem e no processo de cuidado humanizado as vítimas de abuso sexual, atuando como coadjuvante na orientação e no processo de informação sobre os anseios e perspectivas sobre o processo de construção da sexualidade, no intuito de ofertar ao usuário com deficiência a compreensão de suas necessidades, impulsos, desejos e emoções.

A partir das pesquisas realizadas para a construção deste estudo, os autores notaram a necessidade de elaborar outras buscas sobre a temática e área envolvidas em questão, aprofundando-se cada vez mais devido à escassez de material existente. Desta maneira, acreditamos que futuramente teremos outros projetos para apresentar e assim, colaborar com a pesquisa, as comunidades acadêmicas e principalmente com a sociedade.

\section{Referências}

Ainscow, M. (1999). Understanding the development of inclusive schools. London: Falmer Press.

Albuquerque, P., \& Almeida, M. (2010). Sexualidade e deficiência intelectual: um curso de capacitação para professores. Rev. Bras. Estud.Pedagog., 91 (228), 408-123.

Almeida, P. (2009). A educação sexual na deficiência mental. Dissertação. Escola Superior de Educação de Paula Frassineti, 1-68.

Assumpção, F. B., \& Sprovieri, M. H. (1993). Sexualidade e deficiência mental. Editora Moraes.

Baltieri, D. A., Andrade, A. G. (2008). Alcohol and drug consumption among sexual offenders. Forensic Sci Int., 175, 31-35.

Bardin, L. (2016). Análise de conteúdo. Editora Almedina.

Barros, R. D., Williams, L. C., \& Brino, R. F. (2008). Habilidades de autoproteção acerca do abuso sexual em mulheres com deficiência mental. Rev. Bras. Educ. Espec., 14 (1), 93-110.

Bastos, O. M., \& Deslandes, S. F. (2005). Sexualidade e o adolescente com deficiência mental: uma revisão bibliográfica. Cien. Saúde Colet., 10(2), 389-397.

Ministério da Saúde. (2001). Política Nacional de humanização da atenção e gestão do SUS.

Ministério da Saúde. (2003). Política Nacional de Enfrentamento à Violência contra as Mulheres.

Ministério da Saúde. (2005). Seguridade Social e Direitos Humanos. Centro de Direitos Humanos. Coleção Cartilhas Sobre Direitos Humanos. Gênero e Direitos Humanos.

Carvalho, M. E., Andrade, F. C., \& Menezes, C. S. (2010). Equidade de gênero e diversidade sexual na escola: por uma prática pedagógica inclusiva. Editora Universitária. 
Coll, C., Marchesi, A., Palacios, J. (2004). Desenvolvimento psicológico e educação: Transtornos de desenvolvimento e necessidade educativas especiais. Editora Artmed.

Curcino, H. M., Rodrigues, O. M., Maia, A. C., \& Palamim, M. E. (2006). Orientação sexual para jovens adultos com deficiência auditiva. Rev. Bras. Educ. Espec., 12(1), 29-48.

Cyriaco, A. F., Nunn, D., Amorim, R. F., Falcão, D. P., \& Moreno, H. (2017). Pesquisa Qualitativa: conceitos-chave e um breve panorama de sua aplicação em geriatria/gerontologia. Envelhecimento, 11(1), 4-9.

Douglas, M. (1976). Pureza e Perigo. Editora Perspectiva.

Ribeiro, H. C. (1995). Orientação sexual e deficiência mental: estudos acerca da implementação de uma programação. Tese de Doutorado. Universidade de São Paulo.

Fazel, S., Sjösted, G., Langström, N., \& Grann, M. (2007). Severe mental illness and risk of sexual offending in men: a case control study based on Swedish national registers. J ClinPsychiatry., 68, 588-596.

Ferraz, M. I., \& Labronici, L. M. (2009). Perfil da violência doméstica contra a mulher em Guarapuava, Paraná. Cogitare Enferm., 14 (2), 261-268.

Foucault, M. (1993). História da Sexualidade 1: a vontade de saber. Editora Graal.

Gal, E., Schreur, N., \& Engel-Yeger, B. (2010). Inclusion of children with disabilities: Teachers' attitudes and requirements for environmental accommodations. Int. J. Spec. Educ., 25 (2), 89-99.

Gerhardt, T. E., \& Silveira, D. T. (2009). Métodos de pesquisa. UFRGS.

Giami, A. (2004). O anjo e a fera: sexualidade, deficiência mental, instituição. Casa do Psicólogo.

Goldenberg, M. (1997). A arte de pesquisar. Record.

Gonçalvez, R. A., \& Vieira, S. (2004). A avaliação do risco de violência sexual. Psic. Teor. Investig. Prat., 65-80.

Gorla, J. R., Araújo, P.F ., \& Carminato, R. A. (2004). Desempenho psicomotor em portadores de deficiência mental: avaliação e intervenção. Rev. Bras. Cienc. Esporte, 25(3), 133-147

Gregori, M .F. (2008). Limites da sexualidade: violência, gênero e erotismo. Rev. Antrop.,51(2), 575-606.

Hall, D. (1992). The Question of Cultural Identity. In: S. Hall, D. Held and T. McGrew (Eds.), Modernity and Its Futures.

Heighway, S., \& Webster, S. (2008). A Social Skills training Guide for teaching assertiveness, relationship skills and sexual awareness. Future Horizons

Instituto Brasileiro de Geografia e Estatística (IBGE). Censo demográfico.

Maia, A. C., \& Ribeiro, P .R. (2010). Desfazendo mitos para minimizar o preconceito sobre a sexualidade de pessoas com deficiências. Rev. Bras. Educ. Espec., 16 (2), 169-176.

Maia, A. C., \& Camossa, D. A. (2003). Relatos de jovens deficientes mentais sobre a sexualidade através de diferentes estratégias. Paidéia, 12 (24), 205-214.

Mendes, K., Silveira, R. C., \& Galvão, C .M. (2008). Revisão integrativa: método de pesquisa para a incorporação de evidências na saúde e na enfermagem. Texto Contexto Enfermagem, Florianópolis, 17(4): 758-64.

Minayo, M.C. (2011). Pesquisa social. Teoria, método e criatividade. Editora Vozes.

Polit, D. F., \& Beck, C. T. (2011). Delineamento de Pesquisa em Enfermagem. Artmed.

Santos, C. M., Pimenta, C. B., \& Nobre, M. R. (2007).The PICO Strategy for there search question construction and evidence search. Ver. Latino-Am. Enfermagem, 15(3), 508-511.

Schwartzman, J .S. (1999). Síndrome de Down. Memnom.

Souza, M. T., Silva, M.D., \& Carvalho, R. (2010). Revisão integrativa: o que é e como fazer. Einstein, 8(1), $102-106$.

Spitzberg, B. (1999). An analysis of empirical estimates of sexual aggression victimization and perpetration. Violence Vict., 14(3), 241-260.

Villela, W., \& Lago, T. (2007). Conquistas e desafios no atendimento das mulheres que sofreram violência sexual. Cad. Saúde Pub., 23 (2), $471-475$. 